\title{
Optical Recording of Neuronal Excitability in the Rat Dorsolateral Septal Nucleus
}

\author{
HIROSHI HASUO*, TAKASHI AKASU*, MASASHI GOTO*,**, TOSHIHIKO \\ NISHIMURA ${ }^{\dagger}$ AND YOSHIKAZU MUNAKATA* ${ }^{* \ddagger}$ \\ Departments of Physiology*, Medicine ** and Urology ${ }^{\ddagger}$, Kurume University School of Medicine, \\ Kurume 830-0011 and †Department of Physiology, Tokai University School of Medicine, \\ Isehara 259-1100, Japan
}

Key words lateral septum, rat, voltage-sensitive dye, optical recording, pseudo-color image

The septal area participates in a variety of physiological and behavioral processes related to learning, memory, emotions (fear and aggression), as well as autonomic regulation. The lateral septal nuclei, the largest nuclear mass in the septum, receive the massive hippocampo-septal projection, which contains the main axons of the CA1 and CA3 pyramidal neurons [1,2]. Intracellular recordings demonstrated that stimulation of the fimbria/fornix pathway evoked an excitatory postsynaptic potential (EPSP) mediated by an excitatory amino acid in the dorsolateral septal nucleus (DLSN) [3,4]. The principal neurons in the lateral septum which contain $\gamma$-aminobutyric acid (GABA) project primarily to the hypothalamic and amygdaloid areas. In addition to the extraseptal projection, GABAergic neurons participate in local inhibitory circuits within the lateral septum which mediate the inhibitory postsynaptic potential (IPSP), via local axon collaterals $[2,5]$. In this study, the propagation of neuronal activity from the hippocampal CA3 to the septal nuclei was examined with optical recording techniques [6-11].

Parasagittal slices of the rat brain containing both the hippocampal CA3 and the lateral septum were obtained in a manner described previously [12]. Briefly, male Wistar rats (80-150 g) were killed by decapitation. Slices (500 $\mu \mathrm{m}$ in thickness) were cut with a Vibroslice (Campden Instruments) and superfused with ACSF pre-bubbled with $95 \% \mathrm{O}_{2}-5 \% \mathrm{CO}_{2}$. The composition of the ACSF was as follows: 117 $\mathrm{mM} \mathrm{NaCl}, 4.7 \mathrm{mM} \mathrm{KCl}, 2.5 \mathrm{mM} \mathrm{CaCl}, 1.2 \mathrm{mM}$
$\mathrm{MgCl}_{2}, 25 \mathrm{mM} \mathrm{NaHCO}, 1.2 \mathrm{mM} \mathrm{NaHPO}$, and 11 $\mathrm{mM}$ d-glucose (pH 7.4 and 295-305 mOsm). Optical images were acquired using a $128 \times 128$ photodiode array (HR Deltaron 1700, Fuji Photo Film Co., LTD.). With the $10 \times$ objective, each photodiode corresponded to a tissue area of $11.5 \times 11.5 \mu \mathrm{m}$, and the whole array corresponded to an area of $1.48 \times$ $1.48 \mathrm{~mm}$ (Fig. 1). Brain slices were stained with a voltage-sensitive dye, RH-482 $(0.1 \mathrm{mg} / \mathrm{ml})$ (Nippon Kankoh-Shikiso Kenkyusho, Okayama, Japan) for 20 min. The stained slices were mounted on an upright microscope (Optiphoto-2, Nikon) that was equipped with a tungsten-halogen lamp $(100 \mathrm{~W})$, interference filters $(700 \mathrm{~nm})$, a mechanical shutter, and an objective $($ Plan $\times 10)$. Optical responses were recorded as absorption signals of RH-482. Image data files and analysis data files were stored on an IBM PC/AT computer and used for later analysis. Drugs were purchased from the following sources. CNQX and bicuculline methiodide were obtained from Sigma (St Louis, MO). Tetrodotoxin (TTX) was obtained from Wako Pure Chemical Industries, Ltd. All experiments were carried out at $22-24^{\circ} \mathrm{C}$.

Electrical stimulation of the fimbria/fornix pathway induced optical responses near the stimulus electrode and these responses initially spread toward the medial septum by the fimbrial pathway. The optical images then propagated to the dorsolateral portion of the lateral septum (Fig. 2). The apparent velocity of propagation was $0.1-0.2 \mathrm{~m} / \mathrm{s}$. TTX $(1 \mu \mathrm{M})$ blocked the spreading of the optical responses in the slice preparation (Fig. 2A). The responses which had 


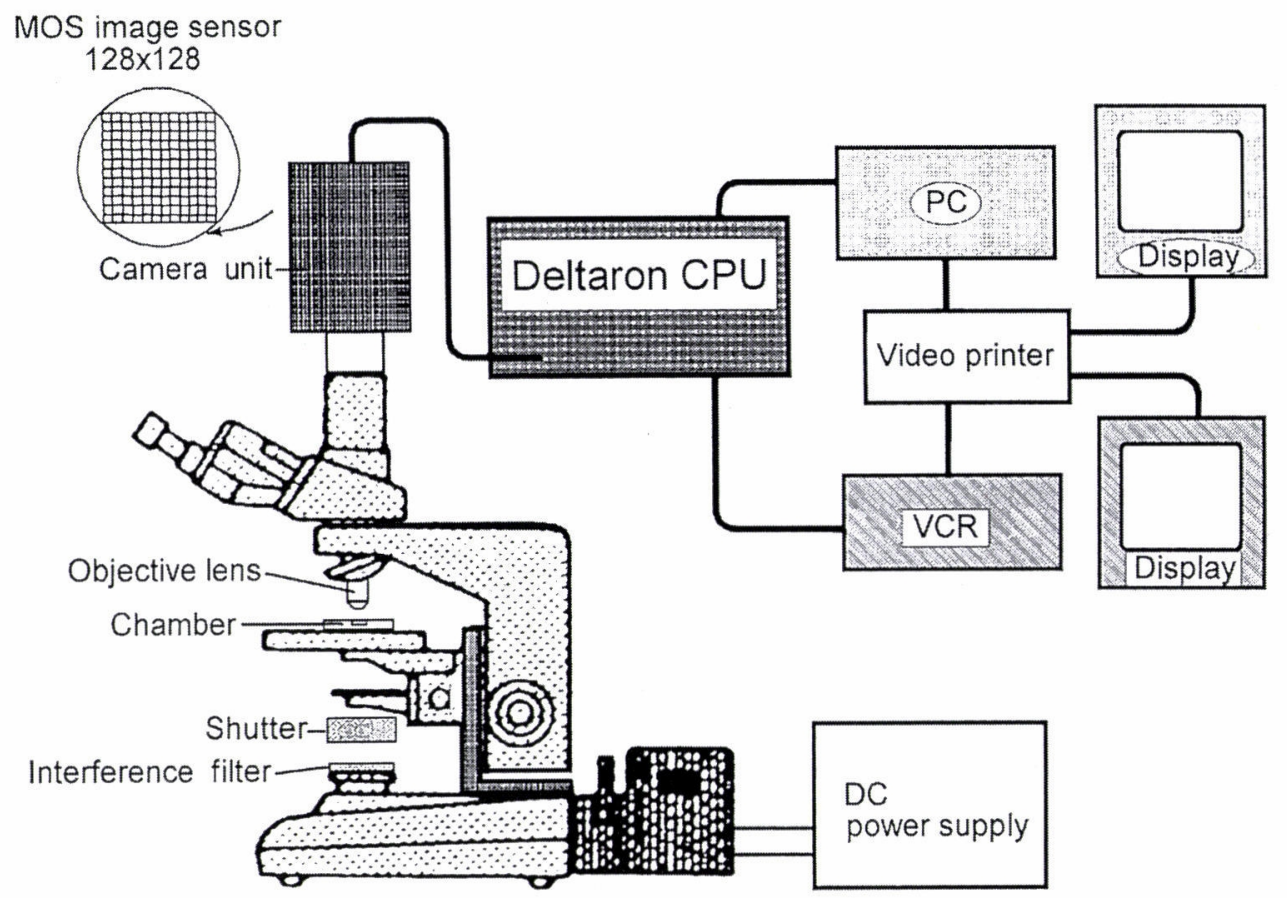

Fig. 1. A schematic diagram of the optical response recording system. The microscope is an Optiphoto-2 (Nikon) with a tungsten-halogen lamp $(100 \mathrm{~W})$. The HR Deltaron 1700 has a camera head which contains the MOS image sensor with a $128 \times 128$ photodiode array. PC: IBM PC/AT computer

\section{Optical response in septum}

A
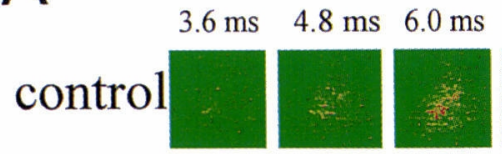

$7.2 \mathrm{~ms} \quad 8.4 \mathrm{~ms} \quad 9.6 \mathrm{~ms}$

$10.8 \mathrm{~ms} \quad 12.0 \mathrm{~ms} \quad 13.2 \mathrm{~ms} 14.4 \mathrm{~ms}$
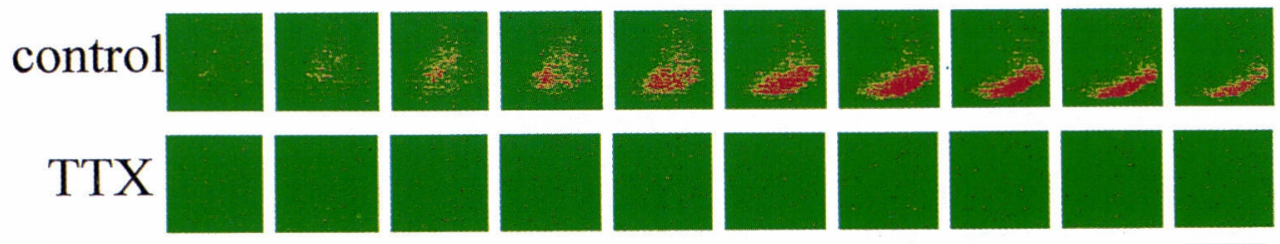

B
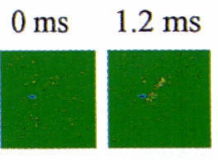

$2.4 \mathrm{~ms} \quad 3.6 \mathrm{~ms}$

$4.8 \mathrm{~ms}$

$6.0 \mathrm{~ms} 7.2 \mathrm{~ms}$

$8.4 \mathrm{~ms}$

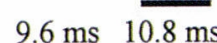

\section{contro}
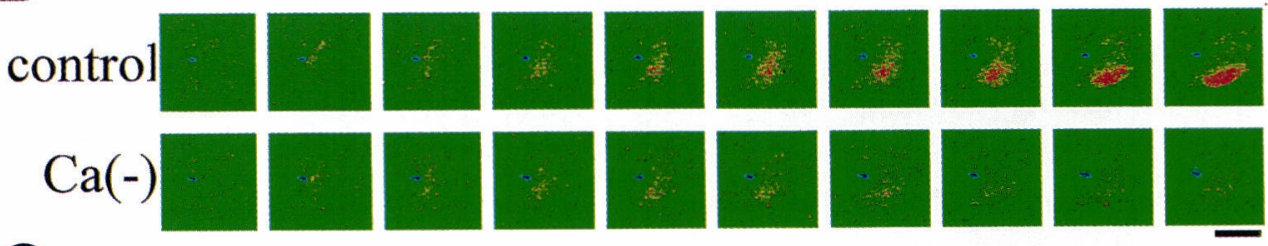

C
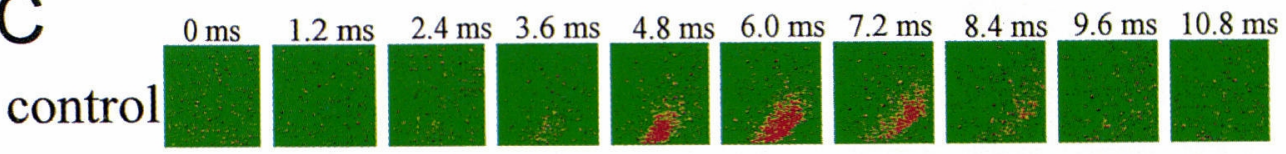

CNQX
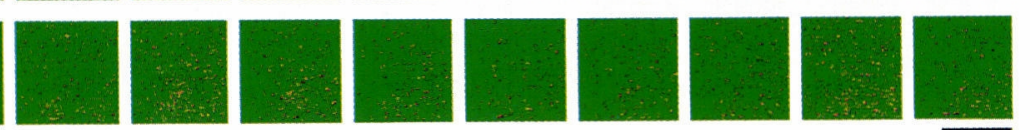

Fig. 2. Optical images in the lateral septal nuclei evoked by stimulation of the fimbria/fornix pathway. A: Effect of TTX $(1 \mu \mathrm{M})$ on the optical signals which propagate to the lateral septum. B: Effect of a low $\mathrm{Ca}^{2+}$ concentration on the optical signals. C: Effect of CNQX, an antagonist for non-NMDA receptors, on the optical signals. Note that these agents block the excitatory optical images in the lateral septum. 
spread to the lateral septum were blocked by a low $\mathrm{Ca}^{2+}$ solution (Fig. 2B). Application of CNQX (10 $\mu \mathrm{M})$ to the Krebs solution also blocked the propagation of the optical images at the DLSN, where excitation signals only occurred near the stimulus electrode (Fig. 2C). In contrast, the application of bicuculline $(50 \mu \mathrm{M})$, a GABAA receptor antagonist, markedly enhanced the optical signals.

Electrical stimulation of the fimbria/fornix pathway which contains axons of the hippocampal CA1 and $\mathrm{CA} 3$ pyramidal neurons, induces an EPSP followed by IPSPs in DLSN neurons [5]. The EPSP was blocked by CNQX $(10 \mu \mathrm{M})$ and AP5 $(50 \mu \mathrm{M})$. The IPSPs were blocked by bicuculline and CGP55845A, GABAA and GABAB receptor antagonists, respectively. In this study, neuronal activity and synaptic transmission between the lateral septum and the hippocampal CA3 area of the rat were examined using optical recording techniques. Excitatory optical responses evoked by stimulation of the fimbrial pathway spread toward the lateral portion of the septum. The optical signals in the lateral septum involve excitatory synaptic transmission mediated by an excitatory amino acid [4]. The principal neurons in the lateral septum which contain $\gamma$-aminobutyric acid (GABA) participate in local inhibitory circuits within the lateral septum, via their local axon collaterals [2]. It has been shown that GABA mediates the IPSPs in the lateral septal neurons [5]. The inhibition of the IPSPs by bicuculline and CGP55845A may result in the disinhibition of inhibitory synaptic transmission in the lateral septum. These results indicate that the propagation of optical signals involve excitatory synaptic transmission in the hippocampo-septal pathway.

ACKNOWLEDGMENTS: This work was supported by a Grant-in-Aid for Scientific Research (B) from the Ministry of
Education, Science, Sports and Culture of Japan (08457017).

\section{REFERENCES}

1. Alonso JR, and Frotscher M. Organization of the septal region in the rat brain: A Golgi/EM study of lateral septal neurons. J Comp Neurol 1989; 286:472-487.

2. Jakab RL, and Leranth C. Septum. In: The Rat Nervous System, 2nd edn, ed. Paxinos G, Academic Press, San Diego, pp 405-442, 1995.

3. Stevens DR, Gallagher JP, and Shinnick-Gallagher P. Intracellular recordings from rat dorsolateral septal neurons, in vitro. Brain Res 1984; 305:353-356.

4. Gallagher JP, and Hasuo H. Excitatory amino acidreceptor-mediated EPSPs in rat dorsolateral septal nucleus neurones in vitro. J Physiol (Lond) 1989; 418:353-365.

5. Gallagher JP, Zheng F, Hasuo H, and Shinnick-Gallagher P. Activities of neurons within the rat dorsolateral septal nucleus (DLSN). Prog Neurobiol 1995; 45:373-395.

6. Grinvald A, Frostig RD, Lieke E, and Hildesheim R. Optical imaging of neuronal activity. Physiol Rev 1988; 68:1285-1366.

7. Salzberg BM. Optical recording of voltage changes in nerve terminals and in fine neuronal processes. Annu Rev Physiol 1989; 51:507-526.

8. Kamino K. Optical approached to ontogeny of electrical activity and related functional organization during early heart development. Physiol Rev 1991; 71:53-91.

9. Sugitani M, Sugai T, Tanifuji M, Murase K, and Onoda $\mathrm{N}$. Optical imaging of the in vitro guinea pig piriform cortex activity using a voltage-sensitive dye. Neurosci Lett 1994; 165:215-218.

10. Tanifuji M, Sugiyama T, and Murase K. Horizontal propagation of excitation in rat visual cortical slices revealed by optical imaging. Science 1994; 266:10571059.

11. Iijima $\mathrm{T}$, Witter MP, Ichikawa M, Tominaga T, Kajiwara $\mathrm{R}$ et al. Entorhinal-hippocampal interactions revealed by real-time imaging. Science 1996; 272:1176-1179.

12. Hasuo H, Shoji S, Gallagher JP, and Akasu T. Adenosine inhibits the synaptic potentials in rat septal nucleus neurons mediated through pre- and postsynaptic $\mathrm{A}_{1}$ adenosine receptors. Neurosci Res 1992; 13:281-299. 